\title{
A ESCOLA ENQUANTO ESPAÇO PRODUTOR DA SAÚDE DE SEUS ALUNOS
}

\author{
LA ESCUELA COMO ESPACIO DE PRODUCCIÓN DE LA SALUD DE \\ SUS ESTUDIANTES
}

SCHOOL AS A HEALTH PROMOTING PLACE FOR ITS STUDENTS

\author{
André Guirland VIEIRA ${ }^{1}$ \\ Denise Rangel Ganzo de Castro AERTS ${ }^{2}$ \\ Sheila CÂMARA ${ }^{3}$ \\ Claudio SCHUBERT ${ }^{4}$ \\ Dóris Cristina GEDRAT ${ }^{5}$ \\ Gehysa Guimarães ALVES ${ }^{6}$
}

RESUMO: A escola tem um compromisso essencial enquanto espaço de desenvolvimento de ações promotoras da saúde de toda a comunidade escolar. No entanto, para que seja potencializadora da qualidade de vida, é necessário que as pessoas sintam-se aceitas e participem do processo de construção deste ambiente. Assim, o objetivo deste estudo é refletir sobre a escola como espaço de produção da saúde e a importância da proposta da escola promotora da saúde. Para tanto, foi realizada pesquisa teórica sobre o ambiente escolar, a inclusão social, e a promoção da saúde na escola. Os resultados apontam para a necessidade de a escola contribuir para o desenvolvimento de habilidades para uma vida saudável, refletindo sobre estilos de vida e promovendo um ambiente de aprendizagem saudável e eficaz para o aluno, com a valorização das individualidades e o estabelecimento de um ambiente que potencialize relações saudáveis, com qualidade de comunicação e com a reflexão sobre as diversidades. Enfatiza-se a importância da atuação crítica, criativa e reflexiva de toda a comunidade escolar na busca da implantação da Escola Promotora da Saúde, desenvolvendo um ambiente prazeroso, alegre e solidário e estimulando a busca compartilhada das perguntas que se apresentam.

PALAVRAS-CHAVE: Saúde escolar. Escola promotora da saúde. Aprendizagem. Comunicação.

1 Doutor em Psicologia; Programa de Pós-Graduação em Promoção da Saúde/ULBRA; andre.vieira@ulbra.br

${ }^{2}$ Médica; Doutora em Clínica Médica; Gerente da Bororo25; daerts.md@ gmail.com

${ }^{3}$ Psicóloga; Doutora em Psicologia; Fundação Universidade Federal de Ciências da Saúde-Porto Alegre

4 Jornalista; Doutor em Educação; Programa de Pós-Graduação em Promoção da Saúde/ULBRA; claudio.schubert@ulbra.br

5 Doutora em Linguística Aplicada; Programa de Pós-Graduação em Promoção da Saúde/ ULBRA; doris.cristina10@gmail.com

6 Socióloga; Psicopedagoga; Doutora em Educação; Programa de Pós-Graduação em Promoção da Saúde/ULBRA; gehysa@terra.com.br 
RESUMEN: La escuela tiene un compromiso esencial como un espacio de actividades promotoras de la salud en toda la comunidad escolar. Sin embargo, para que ella sea capaz de potenciar la calidad de vida, es necesario que las personas sean aceptadas y participen del proceso de construcción de este entorno. El objetivo del estudo es refletir acerca de la escuela como espacio de producción de la salud y, asi, su importancia en la propuesta és de que sea promotora de la salud. Por lo tanto, se realizó una investigación teórica en el entorno escolar acerca de la inclusión social y promoción de la salud en la escuela. Los resultados muestran la necesidad de la escuela contribuir para el desarrollo de las habilidades para una vida saludable, lo que refleja el estilo de vida y la promoción de un ambiente de aprendizaje sano y eficaz para el estudiante. Con la apreciación de los individuos y el establecimiento de un entorno que aprovecha relaciones saludables con una comunicación de calidad y la reflexión sobre la diversidad. Como conclusión Del projecto se percebió la importancia del trabajo crítico, creativo y reflexivo de toda la comunidad escolar en la búsqueda de la aplicación de la Escuela Promotora de Salud, el desarrollo de un ambiente agradable, alegre e del estimulo de la búsqueda compartida de las preguntas que se plantean.

PALAVRAS CLAVE: Salud escolar. Escuela promotora de salud. Aprendizaje. Comunicación

ABSTRACT: The school has a strong commitment with the surrounding community as a space for the development of health promoting actions. However, for this space to be truly potentiating the quality of life, people should feel they are accepted and to participate in the process of building this healthy environment. So the aim of this study is to reflect upon the school as a health production space, and the importance of the health promoting school proposal. For this purpose we conducted a theoretical research on school environment, social inclusion and health promotion in school facilities. Results point to the necessity for school to contribute for the development of healthy life abilities, reflecting upon life styles and promoting a healthy atmosphere for learning, which is appropriate for the student. That includes appraising individualities and establishing an atmosphere that potentiates healthy relations, with communication quality and with reflection upon diversities. It is specially found that teacher's critical, creative and reflexive attitude plays an important role for healthy promoting school establishment, developing a pleasant, joyful and solidary environment, and stimulating joint search for doubts and questions.

KEYWORDS: School health. Health promoting school. Learning. Communication.

\section{Introdução}

A escola é um espaço no qual é preciso desenvolver atividades que fortaleçam o desenvolvimento das crianças e adolescentes que convivem diariamente neste local, contribuindo com a criação de ambientes saudáveis e o fortalecimento de estilos de vida saudáveis, de forma que possa incidir positivamente na vida de toda a comunidade escolar (SILVA et al., 2010). Para tanto, é preciso que os professores estejam atentos a 
este objetivo, estimulando o diálogo e rejeitando qualquer forma de preconceito, seja ele social, cultural, econômico ou linguístico (BAGNO, 2015).

A Escola Promotora da Saúde, divulgada pela Organização Mundial de Saúde (OMS) na década de 1980, teve como propósito fortalecer e ampliar a colaboração entre os setores da educação e da saúde, articulando valores éticos (BUSS, 2007) e estimulando o processo democrático a ser utilizado como ferramenta para o desenvolvimento de habilidades pessoais necessárias para uma vida saudável (MINISTERIO DA SAÚDE, 2002; CORDEIRO, 2008). Esta proposta prima por valorizar os processos afetivos e intelectuais; o tempo de aprender de cada aluno; a participação da comunidade escolar na seleção dos temas a serem trabalhados em sala de aula e a avaliação do processo ensino-aprendizagem (OPAS, 2003).

Quando os conteúdos estão articulados à realidade, tendo como orientação metodológica o diálogo e a reflexão crítica da realidade, promovem a capacidade crítica dos alunos e os auxiliam a fazer escolhas mais saudáveis de vida. O diálogo que fundamenta uma ação pedagógica voltada à realidade do aluno está assentado em uma compreensão que estabelece relações de parceria entre os envolvidos no processo: docente, discentes, direção e pais, onde toda a comunidade escolar envolve-se na ação educacional. Esta racionalidade participativa, consequentemente, vai gerar convivências saudáveis no ambiente escolar (HABERMAS, 2011; PRESTES, 1994).

A educação em saúde nas escolas pode auxiliar os indivíduos a pensarem formas de viver que os protejam, refletindo sobre comportamentos e criando espaços de discussão sobre hábitos saudáveis de vida (GOMES, 2009). Assim, torna-se possível o desenvolvimento de habilidades para o bem viver, que passam a contribuir para a prevenção de comportamentos de risco, promovendo e estimulando a autonomia e a corresponsabilidade (MOURA et al., 2007), fortalecendo aptidões, capacidades e competências e desenvolvendo habilidades para uma vida com mais qualidade (OPAS, 2001, MOURA et al., 2007; GOMES, 2009).

A escola deve ser vista como um espaço produtor da saúde, promovendo a educação integral e o desenvolvimento de habilidades pessoais, garantindo ambientes saudáveis e protetores e desenvolvendo ações que reforcem o bem viver. Nesta direção, várias são as ações que podem ser desencadeadas, desde a proteção do meio ambiente; a conservação de recursos naturais, o reforço do diálogo e o envolvimento, cada vez maior, da comunidade escolar em atividades promotoras da saúde (MINISTÉRIO DA SAÚDE, 2005). 
A Política Nacional de Educação Popular em Saúde reforça a importância do diálogo, considerando a necessidade de que todos estejam envolvidos no processo de construção e aprendizado e em constante transformação e aceitação do novo. Ele ocorre quando cada um, de forma respeitosa, coloca o que sabe à disposição do outro para ampliar o conhecimento crítico de ambos acerca da realidade, contribuindo com os processos de transformação e humanização. Uma escola saudável garante ambientes nos quais a comunicação possibilita o diálogo e neste ocorre o encontro de conhecimentos construídos histórica e culturalmente por sujeitos, portanto, o encontro desses na intersubjetividade (MINISTÉRIO DA SAÚDE, 2012).

Em função da importância do tema, este estudo visa refletir sobre a escola como espaço de produção da saúde e a importância da proposta da escola promotora da saúde.

\section{Escola saudável, inclusão social e produção da saúde}

Um dos fatores necessários para um ambiente escolar saudável, que promova a inclusão social e a produção da saúde, é a comunicação entre os vários atores da comunidade escolar. O processo comunicativo ocorre mediante a associação de novas informações as já armazenadas na memória dos interlocutores (SPERBER, WILSON, 1995). Para aprender, é importante que o educando participe da construção do contexto durante a comunicação em sala de aula, o que o leva à sua inclusão neste processo, juntamente com todas as suas idiossincrasias. Em uma situação que vise a promoção do processo de ensino-aprendizagem (em sala de aula ou não), quanto mais se possibilite o estabelecimento de associações entre seu contexto cognitivo e as novas informações, mais efeitos contextuais se originam; maior número de efeitos contextuais significa mais integração entre o saber que o aluno traz consigo e os novos conteúdos a ele apresentados (GEDRAT, 2015).

Para que a escola seja vista como um espaço de inclusão social e de produção da saúde, precisa contribuir para o desenvolvimento de habilidades para uma vida saudável (OPAS, 2001). A Organização Panamericana de Saúde (OPAS 2002) aponta para a importância da reflexão sobre estilos de vida no ambiente escolar, pois esta irá possibilitar que esse estilo se mantenha na vida adulta. A discussão sobre essas questões pode ser estimulada em atividades de grupo, já que amplia o contato social e reforça as capacidades necessárias para o enfrentamento das demandas da vida (IPPOLITOSHEPHERD, 2012). 
Dentre as habilidades necessárias para o bem viver, salientam-se as sociais e interpessoais, que incluem a comunicação, a capacidade de dizer não, o manejo da agressividade e o incremento da empatia; as cognitivas, que auxiliam na tomada de decisões, no pensamento crítico e na autoavaliação; e as que auxiliam no manejo das emoções, como o estresse (OPAS, 2001, MINTO et al., 2006). É fundamental que uma ação educativa que pretenda promover a saúde considere as especificidades das pessoas que convivem no ambiente escolar. Nesse aspecto, é importante considerar que as pessoas têm diferentes inteligências, assim, aprendem de um modo específico e se relacionam com o conteúdo de forma diferente umas das outras (GARDNER, 2000). Uma ação escolar poderia considerar, na sua organização didático-pedagógica e de convivência, as especificidades dos integrantes da comunidade escolar no seu modo de compreender o processo de ensino-aprendizagem (ARMSTRONG, 2001; ANTUNES, 2006).

Sendo um local no qual convivem alunos, familiares, professores, funcionários e direção, na escola coabitam as diferenças e iniquidades inerentes à vida de relações. Assim, é importante que ela possibilite a reflexão sobre as várias interpretações da realidade, estimulando a discussão sobre princípios éticos, estéticos e dialogando sobre questões que interferem diretamente na vida de cada um. Isso auxilia o entendimento das diversas compreensões a respeito da vida (SECRETARIA MUNICIPAL DE SAÚDE DE SÃO PAULO, 2006) e possibilita às pessoas uma convivência mais saudável na sociedade. Essa reflexão é importante especialmente se considerarmos a cultura midiática na qual vivemos, na qual reina um padrão de beleza que inclui poucos e exclui a maioria. A espetacularização dos programas midiáticos se faz presente na vida da comunidade escolar, na qual, especialmente os alunos-adolescentes, reproduzem os paradigmas veiculados pelas mídias sociais (KELLNER, 2001). Assim, a reflexão ética e estética se alia e pode trazer uma contribuição importante para o tema ambiente saudável na comunidade escolar.

O apoio social e o reforço da autoestima são considerados fatores de resistência às adversidades (GORAYEB, 2002), e auxiliam no enfrentamento e na superação das dificuldades da vida (ASSIS; PESCE; AVANCI, 2006). Isso é propiciado por metodologias participativas e pelo professor (OPAS, 2008), que deve inserir no cotidiano escolar conteúdos necessários para uma vida mais saudável, com as informações necessárias para que os alunos possam responsabilizar-se pela sua saúde. Neste sentido, a escola pode estar atuando como um espaço de produção da saúde e, 
com isso, reduzindo o absenteísmo escolar e incidindo de forma positiva no processo de aprendizagem dos alunos. Isso ocorre em função de auxiliar o indivíduo a avaliar a sua realidade, reconhecer potencialidades e construir um cenário melhor para sua vida. (CERQUEIRA, 2007; EDMUNDO; BITTENCOURT; NASCIMENTO, 2008).

Espaços inclusivos contribuem para o fortalecimento de estilos mais saudáveis de vida (AERTS, 2004). Quando este espaço é a escola, deve estimular a procura de respostas compartilhadas às perguntas que se apresentam; desenvolver um ambiente prazeroso e solidário; abrir espaços para o diálogo e a discussão sobre as diferenças; relacionar contextos, práticas e teorias; abrigar a adversidade; atuar em parceria com alunos, familiares e comunidade; reconhecer a importância da transformação das relações com o ambiente; estimular a participação social; fortalecer a inclusão social (CERQUEIRA, 2007; EDMUNDO; BITTENCOURT; NASCIMENTO, 2008) e o desenvolvimento crítico e criativo de atitudes e de conhecimentos que interferem diretamente na produção social da saúde (EDMUNDO; BITTENCOURT; NASCIMENTO, 2008). Essas estratégias são capazes de contribuir para o fortalecimento de estilos de vida saudáveis, considerando as pessoas dentro dos seus ambientes familiares, comunitários e sociais (GOULART, 2006).

Um importante fator de diversidade cultural entre alunos de uma escola geralmente é a variedade linguística utilizada no ambiente familiar, que também é a mesma que o aluno empregará ao se comunicar na escola. Ao presenciar a realização de uma regra não padrão utilizada pelo aluno, o professor que segue a perspectiva de uma pedagogia culturalmente sensível aos saberes dos alunos considera dois componentes: a identificação e a conscientização da diferença. O primeiro componente, frequentemente, fica prejudicado pela falta de conhecimento dos professores quanto às regras, especialmente em eventos de fala mais informais. O segundo é mais difícil ainda, uma vez que não depende apenas do professor, mas é diretamente influenciado pelo comportamento dos alunos em relação às variedades linguísticas uns dos outros. $\mathrm{O}$ professor precisa ser capaz de conduzir essa etapa sem prejudicar o ensino/aprendizagem do aluno e sem causar interrupções inoportunas (BORTONIRICARDO, 2004).

Considerar a variedade linguística falada pelo aluno, sem julgá-la ou enquadrá-la como estigmatizada, ou prestigiada, é uma forma de conduzir o educando para refletir sobre a sua realidade e os valores que traz de seu ambiente familiar, e construir sua autonomia para a vida. Com isso, o professor estimula o desenvolvimento de condutas e 
atitudes que incidam positivamente na saúde; discute sobre a definição de problemas e riscos à saúde que afetam o processo de aprendizagem; e estimula o desenvolvimento e a manutenção de ambientes saudáveis, propícios ao desenvolvimento físico, mental e social dos escolares (GOULART, 2006; OPAS, 2008). Identificar problemas e buscar soluções criativas para seu enfrentamento é uma habilidade necessária para o desenvolvimento de uma vida saudável e um facilitador de comportamentos que valorizam a vida e respeitam a diversidade cultural e étnica (BOCALETTO, S/D). Esse processo de adoção de estilos saudáveis deve ser refletido dentro de todo o ambiente escolar (MINISTÉRIO DA SAÚDE, 2005), que precisa estar atento a todos os processos de exclusão que estão ocorrendo dentro do espaço escolar.

Sendo a escola um espaço privilegiado de articulação entre os conteúdos científicos e a vida de cada um, a sala de aula deve ser vista como um local dinâmico, de vida, de relações interativas, no qual o aprendizado seja possibilitado pelo estímulo à criatividade, pelo desejo de aprender, pelo respeito às diferenças e desenvolvimento da autonomia. Para isso, é preciso que os professores tenham o desejo de trabalhar com seus alunos e desenvolvam habilidades críticas e reflexivas para este trabalho, pois é esse que os move na direção de uma ação promotora da saúde (AERTS; GANZO, 2011).

É preciso que os professores possam não dar as respostas para seus alunos antes de existirem as perguntas. São elas que expressam os desejos (ALVES, 2004) e é preciso que isso seja estimulado em sala de aula. Conforme demonstrado na novela sociolinguística "A Língua de Eulália", em conversa informal e prazerosa, os alunos podem se sentirem livres para expressarem suas dúvidas e desejos. Com isso, abrem-se amplas oportunidades para o esclarecimento de questões que, sem o devido tratamento, geram preconceitos e situações constrangedoras (BAGNO, 2008).

Um país melhor se constrói com sonhos e inteligência, por isso, é preciso que o lúdico, o prazer e a vida estejam articulados aos conteúdos curriculares (ALVES, 2010). Primeiro, é necessário sonhar e desejar algo, depois, é preciso usar a inteligência para transformar o sonho em realidade e isso somente acontece por meio do desejo. Esta deve ser a base para se trabalhar com os alunos e os conteúdos do currículo escolar precisam estar a serviço da vida e da concretização desses sonhos. Essa talvez seja a principal tarefa da escola promotora da saúde: o desenvolvimento de habilidades que auxiliem os jovens a transformar sonhos em realidade. Para que a escola seja um espaço de saúde, ela deve ter a possibilidade de avaliar a realidade, reconhecendo as 
potencialidades e estimulando ações que possam construir um cenário melhor, com menos violência e mais respeito às diferenças e especificidades de cada um (EDMUNDO; BITTENCOURT; NASCIMENTO, 2008).

A escola é um local de convivências de alunos, familiares, professores, funcionários e direção. É um território no qual coabitam as diferenças, inerentes à vida de relações. Assim, é necessário que a comunidade escolar aprenda a conviver com as iniquidades e pare de lidar com elas a partir da exclusão dos diferentes. Como não há apenas um ponto de vista sobre determinado fenômeno, não pode existir uma única interpretação da realidade. Assim, a escola deve apresentar as várias perspectivas e entendimentos que existem para uma mesma situação e, desta forma, possibilitar a inclusão social de todos os diferentes grupos que existem neste espaço. É importante que a reflexão sobre as diferenças de crenças, religiões, desejos esteja incluída na sala de aula, sendo apresentado que o que se considera diferente é apenas aquele que pensa ou age de forma diversa da hegemônica, porque tem outros valores e princípios discordantes e não porque é menos inteligente ou capaz. Isso possibilita uma infinidade de compreensões a respeito da vida e promove a saúde na medida em que contribui para a inclusão social e a diminuição das desigualdades (SECRETARIA MUNICIPAL DE SAÚDE DE SÃO PAULO, 2006).

A escola que promove a saúde reforça a autoestima e a necessidade de apoio social, considerados como fatores de resistência (GORAYEB, 2002). Atua sobre os fatores e mecanismos que potencializam as capacidades de crianças e adolescentes a enfrentarem e superarem as adversidades e as dificuldades de suas vidas. A essas capacidades de se reequilibrar frente às adversidades utiliza-se o termo resiliência (ASSIS, PESCE; AVANCI, 2006). Todas as pessoas possuem um potencial para desenvolver resiliência em maior ou menor grau. Nesse sentido, a escola é um local privilegiado para potencializar essa capacidade, já que crianças e adolescentes resilientes têm mais chances de viver melhor a vida, tem mais desejo de aprender e melhores condições de superarem os problemas enfrentados dentro da escola (MONTEIRO et al., 2001).

O fenômeno da variação linguística interfere diretamente no ensino e fornece oportunidades para a escola estimular o desenvolvimento da resiliência do adolescente. $\mathrm{Na}$ escola, o aluno expõe-se perante colegas e professores, tendo que enfrentar o preconceito linguístico, que, na verdade, é social, uma vez que a linguística não faz diferenças entre variedades da língua, mas a sociedade o faz. Algumas formas de 
expressão podem estigmatizar socialmente as pessoas, enquanto outras podem valorizálas. Por exemplo, um aluno que diz "nóis" é preterido em favor de outro que utiliza a forma "nós" para se referir à primeira pessoa do plural. Ao fazer isso, a escola pode estar contribuindo para o agravamento ou manutenção das situações de exclusão a que está sujeita a população marginalizada, pois reforça a cultura dominante como referencial exclusivo, ignorando totalmente o dialeto social que o aprendiz domina de acordo com sua origem sociocultural. (BAGNO 2015; BAGNO, 2008)

O modo como a língua é ensinada na escola reforça, tradicionalmente, o modelo da deficiência e tem como propósito a substituição da variedade não padrão pela padrão, quando, na verdade, deveria ter a variedade padrão como meta saudável, sem, no entanto, ignorar a não padrão, que, na maioria das vezes, é a variedade que o aluno traz de seu ambiente familiar. Desprezando a variedade não padrão, está desprezando a natureza do aluno, o seu ser. É preciso que a escola procure despertar a consciência do aluno para a adequação das formas às circunstâncias do processo de comunicação. Ou seja, a variedade linguística será adequada, ou não, dependendo da circunstância, ou situação de comunicação. Nem sempre a norma padrão é a adequada num contexto comunicacional. Ao adotar atitudes como esta, a escola estará reforçando o modelo da diferença e adotando estratégias para o ensino da língua materna nas quais as formas alternativas de linguagem podem conviver harmoniosamente em sala de aula, criando um ambiente saudável e sem preconceitos para o desenvolvimento das habilidades linguísticas dos alunos (CAMACHO, 2001; PEREIRA, SILVA; SILVA, 2013).

A escola que promove a saúde deve atuar de forma a fortalecer o potencial criativo dos alunos, de suas famílias e de toda a comunidade escolar (DAERTS; GANZO, 2010). Quando age desta forma, priorizando o desenvolvimento de habilidades para a vida; de relações interpessoais saudáveis; estimulando a afetividade e a autonomia, está contribuindo para o aumento do bem-estar individual e coletivo e, portanto, da qualidade de vida. Assim, é preciso que os educadores estejam atentos às estratégias que utilizam em sala de aula e nos contatos com os alunos e suas famílias a fim de possibilitar o resgate da autoestima e valorizar as capacidades individuais (MONTEIRO, 2001). Pensamento crítico e criativo, autoconhecimento, comunicação eficaz, autoestima, autonomia, compromisso social e manejo das emoções auxiliam no enfrentamento das dificuldades de aprendizagem e estão entre as habilidades essenciais para uma vida mais saudável (OPAS, 2008). Nesse sentido, o desenvolvimento de habilidades pessoais é utilizado como ferramenta das ações educativas, devendo centrar 
sua atenção na articulação da teoria com a prática. Para agir nesta direção, os professores necessitam de momentos periódicos de reflexão sobre a teoria, articulando-a com a vida cotidiana e relacionando a teoria e a vida nos encontros em sala de aula (FREIRE, 2011). Para isso, necessitam do acompanhamento e da educação continuada, assim, estarão mais aptos a realizarem essa articulação e mais preparados para adotarem um estilo de vida saudável, desenvolvido a partir da reflexão sobre atitudes, conhecimentos e hábitos que favoreçam o bem-estar (GOMES, 2009).

A articulação da teoria com a prática e a discussão sobre o desenvolvimento de habilidades para a vida e os conteúdos necessários para uma vida mais saudável, possibilitam que cada sujeito tenha a possibilidade de ser capaz de responsabilizar-se pela sua saúde. Assim, ao sair da escola, esse indivíduo poderá incorporar-se à comunidade e socializar as habilidades desenvolvidas com as pessoas com quem convive e, com isso, contribuir para uma sociedade mais saudável e para uma melhor consciência do que é melhor para si.

\section{Escola promotora da saúde}

Para que a escola seja promotora da saúde, é importante que assuma sua responsabilidade como potencializadora do ser saudável. Neste contexto, as áreas prioritárias são: saúde mental; saúde oral; alimentação saudável; atividade física; ambiente escolar; promoção da segurança e prevenção de acidentes; saúde sexual e reprodutiva; educação para o consumo (OPAS, 2008). A cultura da mídia é industrial, pois se organiza na produção de produtos destinados às massas de acordo com as especificidades de gênero, categoria social e poder de consumo dos indivíduos. No consumo dos produtos midiáticos, sejam eles materiais ou conceituais, criam-se identidades. Esses paradigmas e modelos de identidades são os meios pelos quais os indivíduos se inserem nas sociedades locais, mas com desdobramentos e apoiados na cultura global (KELLNER, 2001). Esta reflexão é importante quando se pensa num ambiente escolar saudável onde a maioria dos alunos está no processo de construção de sua identidade em meio à diversidade de modelos que as mídias sociais dispõem.

É necessário que a escola promotora da saúde estimule os alunos a pensarem criticamente e a entenderem a relação dos conteúdos científicos com a vida de cada um, desenvolvendo programas e projetos capazes de contribuir para a construção de valores pessoais, e dentre eles salienta-se o cuidado com sua vida e a saúde. Nesse sentido, deve propiciar espaços dialógicos, problematizadores e inclusivos, nos quais o aluno possa 
construir consciência crítica sobre si próprio e aprender a cuidar melhor de si (FREIRE, 2015).

Sabe-se que os indivíduos estruturam sua personalidade na cultura do seu meio, no qual acontecem as relações sociais (HABERMAS, 2011). Na medida em que a cultura dos integrantes da comunidade escolar for valorizada, cria-se a possibilidade de desenvolver ambientes saudáveis. Assim, as ações padronizadas e previamente decididas acabam sendo substituídas por propostas nas quais os sujeitos tenham maior chance de construir caminhos emancipadores e transformadores.

Ao se abrir para o diálogo, a escola estará contribuindo para a saúde, para a inclusão social (AERTS, 2004) e para a facilitação do aprendizado dos conteúdos teóricos necessários a um melhor enfretamento da vida. É importante que alunos e professores se apropriem de sua vida e que esse movimento seja estimulado na vida em sociedade. Essa é uma ação que visa o melhor aproveitamento do capital humano, sendo o resultado do compartilhamento de informações fundamentais para o desenvolvimento da autonomia e para a tomada de decisões. Esse movimento é consequência do desenvolvimento da autonomia e da responsabilização dos indivíduos pela sua vida individual e pelo seu papel na sociedade, evidenciando os mecanismos de discriminação e exclusão que se criam nesses territórios (MOREIRA et al., 2007).

Pensar a escola como um espaço promotor da saúde é acreditar que, para ser saudável, o indivíduo deve ter a possibilidade de avaliar a sua realidade, reconhecendo as potencialidades e dificuldades para construir um cenário melhor para sua vida. Nesta perspectiva, é importante que perceba o seu entorno e aja sobre ele de forma a criar alternativas promotoras da saúde. Da mesma forma, é preciso tomar consciência sobre o contexto no qual as situações favoráveis e adversas são produzidas para que, a partir deste contato, possam ser definidas ações que se dirijam a um melhor bem-estar para si (CERQUEIRA, 2007; EDMUNDO; BITTENCOURT; NASCIMENTO, 2008). Sendo a escola um espaço de aprendizagem e de construção do conhecimento, deve propiciar a pesquisa e construir socialmente a saúde a partir da participação da comunidade; da solidariedade, do diálogo e do estabelecimento de relações afetivas. É nela que se desenvolvem conhecimentos, habilidades e atitudes pessoais para o enfrentamento da vida, para a consolidação da saúde e para o aprendizado do autocuidado (MINISTÉRIO DA SAÚDE, 2005).

Uma escola saudável desenvolve um ambiente prazeroso, alegre e solidário; estimula seus alunos a buscarem respostas de modo compartilhado às perguntas que se 
apresentam e a conviver com a diversidade cultural e com as adversidades inerentes à vida; abre espaços para o diálogo e a discussão sobre as diferenças; estimula o professor a dedicar atenção ao processo de aprendizagem do aluno e à parceira com as famílias e a comunidade escolar, relacionando a teoria com a vida cotidiana; e reconhece a importância da aquisição de hábitos saudáveis que transformem a relação com o ambiente. Isso fortalece a participação social e a inclusão social (CERQUEIRA, 2007; EDMUNDO; BITTENCOURT; NASCIMENTO, 2008). Essas questões devem abordar a importância das transformações fundamentais para a construção de uma vida saudável e devem estar inseridas no projeto pedagógico da escola (CERQUEIRA, 2007). Sua contribuição para a produção da saúde está em construir um cidadão crítico e criativo; com autonomia e sabedor de seus direitos e deveres; e com habilidades para viver bem a sua vida (EDMUNDO; BITTENCOURT; NASCIMENTO, 2008).

A escola que promove a saúde deve trabalhar com o sujeito integral, considerando as pessoas dentro dos seus ambientes familiares, comunitários e sociais. Para cumprir seu papel, promove a autonomia, a criatividade e a participação e desenvolve a aprendizagem de forma mais tranquila e efetiva (GOULART, 2006). Para tanto, é imprescindível a parceria com outros setores da sociedade. Neste sentido, os profissionais da saúde e a comunidade escolar devem ser chamados para contribuir com os temas a serem abordados, propondo o desenvolvimento de condutas e atitudes que incidam positivamente na saúde.

As experiências construtivas são a chave para o fortalecimento de habilidades pessoais (OPAS, 2008), sendo este um dos papéis do professor em sala de aula. O professor deve estimular a capacidade de identificar problemas e buscar soluções criativas para seu enfrentamento. Isso possibilita a construção de "pontes" entre o que se sabe (conhecimentos adquiridos), o que se pensa, sente ou acredita e o que e como se faz. Com isso, passa a ser um facilitador do acesso às informações e cria condições para que se discutam os comportamentos de valorização da vida, evitando normatizar ou padronizar atitudes de respeito à diversidade cultural e étnica (BOCALETTO, 2012). Ele deve procurar compreender o que determina que uma pessoa queira ou não optar por um estilo de vida saudável e possa atuar a partir dessa perspectiva. (OPAS, 2008).

Esse processo de adoção de estilos saudáveis necessita ser refletido dentro do ambiente escolar (MINISTÉRIO DA SAÚDE, 2005), evitando padronizar comportamentos, pois essa é uma forma de homogeneizar as pessoas, excluir os diferentes dentro da escola e gerar o fracasso escolar. A escola deve observar os alunos 
que estão sendo excluídos do processo de aprendizagem e oferecer atividades nas quais poderá ser explorado o potencial do aluno e valorizada sua individualidade. Para isso, é preciso que os professores estejam capacitados a observarem se e como esses processos ocorrem no cotidiano escolar.

\section{Reflexões finais}

A escola pode contribuir no fortalecimento de habilidades necessárias para o desenvolvimento de estilos de vida saudáveis na medida em que os professores passem a atuar de forma mais crítica, criativa e reflexiva, pois são os responsáveis por coordenarem esses processos. Com isso, estarão agindo em prol da inclusão e da promoção da saúde de toda a comunidade escolar. Ao entenderem que sua tarefa não é somente transmitir o conteúdo curricular, potencializam a formação de alianças e lideranças positivas e minimizam as chances do surgimento de espaços agressivos. Por sua vez, o currículo escolar deve estar em consonância com as Diretrizes Curriculares Nacionais e apoiar conhecimentos teóricos que garantam os direitos dos alunos, o repeito às suas particularidades e que sejam desenvolvidos de forma dialógica, crítica e criativa.

A comunicação que estimula a autonomia do aluno, abrindo-lhe oportunidades para exercer a resiliência, ao aceitá-lo com suas idiossincrasias linguísticas e culturais é fator imprescindível numa pedagogia que visa não só seu aprendizado, mas também sua saúde. Quando essas questões estão presentes, é possível que a escola possa estar contribuindo para o desenvolvimento de alunos e de professores mais capazes de cuidarem bem de si e de contribuírem para a construção de uma sociedade mais fraterna, solidária e saudável. Isso requer esforço e exige do educador saúde emocional.

Os trabalhadores da saúde podem dar uma contribuição importante ao desenvolvimento desta escola promotora da saúde, pois pode oferecer aos professores a reflexão sobre temas relacionados à saúde, de forma que possam trabalhar esses conteúdos em sala de aula e assessorar na identificação de problemas e prioridades de saúde para que esses possam ser discutidos na escola. Por sua vez, os professores podem atuar de forma a auxiliar os alunos a pensar em relação ao seu estar no mundo e a um viver saudável.

\section{Referências}


AERTS, D. et al. Promoção de Saúde: a convergência entre as propostas de vigilância da saúde e da escola cidadã. Cad. de Saúde Pública. Rio de Janeiro, 20 (4):1020-128, jul-ago, 2004.

AERTS, D.; GANZO, C. A felicidade possível. Porto Alegre: Bororó, 2011.

ALVES, R. Conversas sobre educação. Campinas, SP: Verus Editora, 2010.

ALVES, R. O Desejo de ensinar e a arte de aprender. Campinas: Fundação Educar. D. Paschoal. 2004.

ALVES, R.; DIMENSTEIN, G. Fomos maus alunos. São Paulo: Editora Papirus, 2009.

ALVES, G. capacitação em vigilância da saúde fundamentada nos princípios da educação popular. Tese de doutorado. PUCRS: Porto Alegre, 2006.

ARMSTRONG, T. Inteligências múltiplas na sala de aula. Porto Alegre: ARTMED Editora, 2001.

ANDRADE, L. O. M.; CUNHA, I. C. H. B. Promoção da Saúde e Cidades/Municípios Saudáveis: propostas de articulação entre saúde e ambiente. In.: MINAYO, M. C. S; MIRANDA, A. C. Saúde e ambiente sustentável: estreitando nós. Rio de Janeiro: Fiocruz, 2001.

ANTUNES, C. Inteligências múltiplas e seus jogos: introdução. Vol.1, Petrópolis, RJ, Vozes, 2006.

ASSIS, S. G.; PESCE, R. P.; AVANCI, J. Q. Resiliência: enfatizando a proteção dos adolescentes. Porto Alegre: Artmed, 2006.

BAGNO, M. A língua de Eulália. São Paulo: Contexto, 2008.

BAGNO, M. Preconceito linguístico. São Paulo: Parábola, 2015.

BOCALETTO, E. M. Referenciais Teóricos e Práticas da Escola Promotora da Saúde e Qualidade de Vida. Disponível em: <http://www.fef.unicamp.br/departamentos/deafa/qvaf/livros/livros_texto_ql_saude_col e_af/saude_coletiva/saude_coletiva_cap12.pdf>. Acesso em: 25 já. 2016.

BORTONI-RICARDO, S. M. Educação em Língua Materna. A sociolinguística na sala de aula. São Paulo: Parábola, 2004.

BRASIL. A Promoção da Saúde no Contexto Escolar. Informe Técnico-Administrativo. Projeto Promoção da Saúde. Secretaria de Políticas de Saúde. Ministério da Saúde. Revista de Saúde Pública. Rio de Janeiro, p. 533 - 535. 2002.

BUSS, P. M. e FERREIRA, J. R. (org.) Promoção da Saúde e a Saúde Pública: contribuição para o debate entre as escolas de saúde pública da América Latina. RJ, 1998 (mimeo). 
BUSS, P. Uma Introdução ao Conceito de promoção da Saúde. In.: CZERESNIA, D; FREITAS, C.M. (Org.). Promoção da saúde: conceitos, reflexões, tendências. Rio de Janeiro: Fiocruz, 2003. cap. 1.

BUSS, P.M.; FILHO, A.P. A Saúde e seus Determinantes Sociais. PHYSIS: Rev. Saúde Coletiva, Rio de Janeiro, 2007, 17(1):77-93.

CAMACHO, R. Sociolinguística. In: MUSSALIN, F. e BENTES, A.C. (orgs.) Introdução à Linguística, v.1. São Paulo: Cortez, 2001.

CERQUEIRA, M. T. A Construção da Rede Latino Americana de Escolas Promotoras da Saúde. In.: MINISTÉRIO DA SAÚDE; ORGANIZAÇÃO PAN-AMERICANA DE SAÚDE. Escolas Promotoras de Saúde: experiências no Brasil. Série Promoção da Saúde nº 6. Brasília, 2007.

CORDEIRO, J. C. A promoção da saúde e a estratégia de cidades saudáveis; um estudo de caso no Recife e Pernambuco. Tese de Doutorado. Fundação Oswaldo Cruz, 2008.

EDMUNDO, K; BITTECOURT, D; NASCIMENTO, G. Saúde e educação. Salto para o Futuro. Ano XVIII. Boletim 12, agosto de 2008. Disponível em: <http://tvbrasil.org.br/fotos/salto/series/182321Saude.pdf>. Acesso em: 12 fev. 2016.

FRACOLLI, L.A.; BERTOLOZZI, M.R. A abordagem do processo saúde-doença das famílias e do coletivo. Ministério da Saúde/Universidade de São Paulo/IDS, 2003. Disponível em: <http://www.ids-saude.org.br/enfermagem>. Acesso em: 23fev. 2016.

FREIRE, P. A importância do ato de ler: em três artigos que se completam. 38. ed. São Paulo: Cortez, 2011.

FREIRE, P Pedagogia da autonomia: saberes e necessários à prática educativa. São Paulo: Paz e terra, 2015.

GARDNER, H. Inteligências Múltiplas: A teoria na prática. Porto Alegre, Artes mèdicas, 1995.

GEDRAT, D.C. Relevância e Ensino: reflexão sobre a noção apropriada de contexto nas situações de ensino e aprendizagem de língua portuguesa à luz de teorias pragmáticas da comunicação. Letras \& Letras, v. 31, n.2, 2015. P. 36-60. Disponível em: <http://www.seer.ufu.br/index.php/letraseletras/article/view/30557>. Acesso em: 03 mar. 2016.

GENTILE, M. Promoção da saúde e município saudável. São Paulo: Vivere, 2001.

GOMES, J.P. As Escolas Promotoras de Saúde: uma via para promover a saúde e a educação para a saúde da comunidade escolar. Educação, Porto Alegre, v. 32, n. 1, 2009, p. 84-91, jan./abr.

GORAYEB, R. O ensino de habilidades de vida em escolas no Brasil. Psicologia, Saúde \& Doenças, v. 3, n.2, 2002, 213-217.

GOULART, R.M. Promoção de saúde e o programa escolas promotoras da saúde. Caderno de Saúde. Vol.1. N. 1. 2006, p. 5 - 13. 
HABERMAS, J. Teoría de la acción comunicativa: complementos y estudios previos. Tradução de Manuel J. Redondo. 3. ed. Madrid: Ediciones Cátedra, 2011.

KELLNER, D. A cultura da mídia: identidade e política entre o moderno e o pósmoderno. Bauru, SP: EDUSC, 2001.

IPPOLITO-SHEPHERD, J.A Promoção da Saúde no Âmbito Escolar: A Iniciativa Regional Escolas Promotoras da Saúde. Caderno das escolas promotoras da saúde. Sociedade Brasileira de Pediatria, 2012. Disponível em: <http://www.sbp.com.br/img/cadernosbpfinal.pdf>. Acesso em 27 fev. 2016.

MENDES, E. Uma Agenda para a saúde. São Paulo: Hucitec, 2006.

MINISTÉRIO DA SAÚDE. A promoção da saúde no contexto escolar. Informes Técnicos Institucionais. Projeto de Promoção da Saúde. Secretaria de Políticas de Saúde. Rev. Saúde Pública. V.36. n. 4. São Paulo, agosto, 2002.

MINISTÉRIO DA SAÚDE. A escola que produz saúde. Série F. Comunicação ee educação em saúde. Secretaria de gestão do trabalho e da educação em saúde. Departamento da Gestão em Educação em Saúde. MS: Brasília, 2005.

MINISTÉRIO DA SAÚDE. Política Nacional de Educação Popular em Saúde. Comitê Nacional De Educação Popular Em Saúde - CNEPS. Brasília - DF, 2012. <http://www.crpsp.org.br/diverpsi/arquivos/PNEPS-2012.PDF>. Acesso em 15 mar. 2016.

MINTO, E. C.; PEDRO, C. P.; NETTO, J. R. C.; BUGLIANI, M. A. P.; GORAYEB, R. Ensino de habilidades de vida na escola: uma experiência com adolescentes. Psicologia em Estudo, Maringá, v. 11, n. 3, p. 561-568, set./dez. 2006.

MOREIRA, J.; SANTOS, H. R.; TEIXEIRA, R. F.; FROTTA, P. R. O. Educação popular em saúde: a educação libertadora mediando a promoção da saúde e o empoderamento. Contrapontos. V.7; n. 3, p. 507-521, 2007.

MONTEIRO, D. S. A. Resiliência e pedagogia da presença: intervenção sócio-pedagógica no contexto escolar. In.: BELLO, José Luiz de Paiva. Pedagogia em Foco, Vitória, 2001. Disponível em: <http://www.pedagogiaemfoco.pro.br/fundam01.htm>. Acesso em: 15 fev. 2016.

MOURA, J. B.; LOURINHO, L. A.; VALDÊS, M. T. M.; FROTA, M. A.; CATRIB, A. M. F. Perspectiva da epistemologia histórica e a escola promotora da saúde. Rev. História, Ciência e Saúde. Rio de Janeiro: Manguinhos. V. 14, n.2, p. 489 - 501, 2007.

ORGANIZAÇÃO PANAMERICANA DE SAÚDE. Por una juventud sin tabaco: adquisición de habilidades para una vida saludable. Publicación Científica y Técnica no. 579. Oficina Sanitaria Panamericana. Oficina Regional de la OMS, 2001.

ORGANIZAÇÃO PAN-AMERICANA DE SAÚDE. Municípios e comunidades saudáveis- Guia dos prefeitos para promover qualidade de vida. Divisão de promoção e proteção da saúde. Washington DC, 2002. 
ORGANIZAÇÃO PANAMERICANA DE SAÚDE. Escolas promotoras da saúde: fortalecimento da iniciativa regional. estratégias e linhas de ação 2003-2012. Washington: OPS/OMS, 2003. Disponível em: <http://www.cepis.opsoms.org/bvsdeescuelas/fulltext/EPSportu.pdf>. Acesso em: 17 mar. 2016.

PAIVA, F. S.; RODRIGUES, M. C. Habilidades de vida: uma estratégia preventiva ao uso de substâncisa psicoativas no contexto educativo. Estudos e pesquisas em Psicologia. UERJ, ano 8, n. 3, p 672-684, 2008.

PEREIRA, B. G.; SILVA, J. S.; SILVA, J. B. Como trabalhar variação linguística e gramática em sala de aula: uma reflexão. Ribanceira - Revista do Curso de Letras da UEPA. Belém. Vol. 1. n. 1.Jul-Dez.2013 ISSN Eletrônico: 2318-9746.

PRESTES, N. H. A razão, a teoria crítica e a educação: In: Teoria Crítica e a Educação. Petrópolis: Vozes, 1994.

SECRETARIA MUNICPAL DE SAÚDE DE SÃO PAULO. Manual de atenção à saúde do Adolescente. São Paulo (Cidade). Secretaria da Saúde. Manual de atenção à saúde do adolescente. Coordenação de Desenvolvimento de Programas e Políticas de Saúde. CODEPPS. São Paulo: SMS, 2006.

SILVA, L. K.; SENA, R .R.; GRILLO, M. J. C.; HORTA, N. C. Formação do enfermeiro: desafios para a promoção da saúde. Esc Anna Nery. Rev Enferm. 14 (2), 368-376, 2010.

SPERBER, D.; WILSON, D. Relevance: communication and cognition. Oxford: Blackwell, 1986/1995.

WORLD HEALTH ORGANIZATION (WHO). (1986) Conferência Internacional sobre Promoção da Saúde. Carta de Ottawa para a Promoção da Saúde. Canadá, 1986.

\section{Como referenciar este artigo}

ALVES, Gehysa Guimarães et al. A escola enquanto espaço produtor da saúde de seus alunos. Revista Ibero-Americana de Estudos em Educação, Araraquara, v. 12, n. 2, p. 916-932, 2017. Disponível em: <http://dx.doi.org/10.21723/riaee.v12.n2.8492>. EISSN: $1982-5587$.

Recebido em: 31/03/2016

Aprovação final em: 30/03/2017 